\title{
Anti-HCMV activity by an irreversible p97 inhibitor LC-1310
}

\author{
Yan Wang ${ }^{1,2} \cdot$ Ruben Soto-Acosta ${ }^{1} \cdot$ Rui Ding $^{1} \cdot$ Liqiang Chen $^{1} \cdot$ Robert J. Geraghty $\mathbb{D}^{1}$
}

Received: 1 November 2020 / Accepted: 2 December 2020 / Published online: 9 January 2021

(c) The Author(s), under exclusive licence to Springer Science+Business Media, LLC part of Springer Nature 2021

\begin{abstract}
The AAA+ (ATPase associated with various cellular activities) protein p97, also called valosin-containing protein, is a hexameric ring ATPase and uses ATP hydrolysis to unfold or extract proteins from biological complexes. Many cellular processes are affected by p97 including ER-associated degradation, DNA damage response, cell signaling (NF-kB), cell cycle progression, autophagy, and others. Not surprisingly, with its role in many fundamental cellular processes, p97 function is important for the replication of many viruses. We tested irreversible p97-targeting compounds for their ability to inhibit the replication of multiple viruses compared to the known p97 inhibitors NMS-873 and CB-5083. Our results indicate that overall cellular toxicity for $\mathrm{p} 97$ compounds provides a challenge for antivirals targeting p97. However, we identified one compound with sub-micromolar activity against human cytomegalovirus and improved cell viability to provide evidence for the potential of irreversible p97 inhibitors as antivirals.
\end{abstract}

\section{Graphical Abstract}
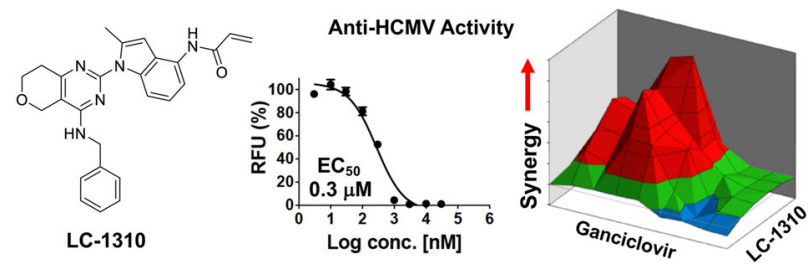

Keywords p97 $\cdot$ Valosin-containing protein $\cdot$ p97 inhibitors $\cdot$ Human cytomegalovirus $\cdot$ Antiviral

\section{Introduction}

The AAA+ (ATPase associated with various cellular activities) protein $\mathrm{p} 97$, also called valosin-containing protein, is a hexameric ring ATPase and uses ATP hydrolysis to unfold or extract proteins from biological complexes [1].

Liqiang Chen

chenx462@umn.edu

Robert J. Geraghty

gerag012@umn.edu

1 Center for Drug Design, College of Pharmacy, University of Minnesota, Minneapolis, MN 55455, USA

2 Present address: Translational Medicine R\&D Center, Shenzhen Institutes of Advanced Technology, Chinese Academy of Sciences, Shenzhen 518055, China
Extracted proteins are often ubiquitylated to facilitate their degradation by the 26S proteosome [2]. Many cellular processes are affected by p97 including ER-associated degradation (ERAD), DNA damage response, cell signaling (including NF- $\mathrm{KB}$ ), cell cycle progression, autophagy, and others. p97 is one of the most abundant proteins in cultured cells and yet upregulation of p97 levels in many cancers can signal a poor clinical outcome [3]. Therefore, p97 has been put forward as an anticancer target and a p97 inhibitor entered into a phase I clinical trial [4].

The p97 monomer has three major domains. The p97 $\mathrm{N}$-terminal domain can interact with a wide range of adaptor proteins to result in different subcellular locations and substrate recognition. The two other domains, D1 and D2, have ATPase activity, however, ATP hydrolysis by D1 is relatively inactive compared to that of D2 [5]. The D1 domains promote hexamer formation and overall structural integrity. The D2 domain likely provides the major ATP 
hydrolysis activity for hexameric p97 extraction of ubiquitylated proteins.

A variety of molecular interactions have been described for $\mathrm{p} 97$ inhibitors. Eeyarestatin features a nitrofuran group thought to bind D1 and an aromatic domain that may interact with membranes to increase target specificity [6]. UPCDC30245 binds at the junction between D1 and D2 and may prevent conformational changes resulting from ATP binding [7]. NMS-873 probably also binds at the D1/ D2 junction and is not competitive with ATP for inhibition $[8,9]$. CB-5083 binds D2 and is competitive with ATP $[10,11]$. CB5083 has been in a phase I trial with the ultimate goal of advancing it as a solid tumor or multiple myeloma treatment [4], however, the trial was halted due to adverse effects perhaps caused by unintended inhibition of phosphodiesterase-6 [12].

Not surprisingly, with its role in a myriad of fundamental cellular processes, p97 function is important for the replication of many viruses. Viruses rely upon processes such as ERAD, ribosome maintenance, mRNA transport, and autophagy to avoid host detection, facilitate viral protein expression and virus replication, including particle assembly and release [1, 12-14]. Reduction of p97 expression, mainly by siRNA knockdown, inhibits coronavirus $(\mathrm{CoV})$, human cytomegalovirus (HCMV), enterovirus, Rift Valley fever virus, chikungunya virus, influenza A virus (IAV), poliovirus, and West Nile virus replication [15-22]. Published p97 inhibitors have also displayed antiviral activity against many of the aforementioned viruses and a baculovirus [16, 17, 19, 20, 22-27].

We recently described the design and synthesis of novel irreversible small molecule inhibitors targeting p97 [28]. We tested representatives of those irreversible p97-targeting compounds for their ability to inhibit the replication of multiple viruses compared to the known p97 inhibitors NMS-873 and CB-5083. Our results indicate that overall cellular toxicity for $\mathrm{p} 97$ compounds provides a challenge for antivirals targeting p97. However, we identified one compound that demonstrated sub-micromolar activity against human cytomegalovirus with improved cell viability to provide evidence for the antiviral potential of these irreversible p97 inhibitors.

\section{Results/discussion}

The ring ATPase p97 is involved in many important cellular processes such as ERAD, autophagy, endosomal trafficking, and regulation of multi-protein complex function. Viruses rely upon many cellular processes to establish and spread to new hosts; therefore, it is not surprising that $\mathrm{p} 97$ would be implicated as an important cellular factor for the replication of many viruses. We have recently published the design and synthesis of a series of irreversible p97 inhibitors [28] and were interested in testing representatives of those and other known p97 inhibitors (Fig. 1) for possible antiviral activity using a variety of viruses.

HCMV is a human herpesvirus. Herpesviruses are enveloped viruses with large double-stranded DNA genomes ( $236 \mathrm{kbp}$ for HCMV). Herpesvirus genome replication, capsid assembly, and gene transcription occur in the nucleus. Gene expression involves a regulatory cascade pattern during lytic replication where genes are expressed early, midway or late in virus replication. HCMV requires p97 expression for virus replication and known p97 inhibitor, NMS-873, reduced virus replication [16]. We tested our irreversible p97 inhibitors for inhibition of HCMV replication in primary human foreskin fibroblasts (HFFs). Our approach was to inoculate HFFs with HCMV ADCREGFP, a green fluorescent protein (GFP) reporter virus [29], add compounds, and assess GFP expression 6 days later as a measure of virus replication and spread. We have used the virus-dependent GFP expression assay to evaluate many types of inhibitors [30-32]. All p97 inhibitors were evaluated in dose-response experiments for antiviral activity $\left(\mathrm{EC}_{50}\right)$ and cell viability $\left(\mathrm{CC}_{50}\right)$. Only LC1310 showed clear antiviral activity $\left(\mathrm{EC}_{50} 0.3 \mu \mathrm{M}\right)$ in the absence of toxicity $\left(\mathrm{CC}_{50} 12 \mu \mathrm{M}\right)$ with a tissue culture therapeutic index $\left(\mathrm{EC}_{50} / \mathrm{CC}_{50}\right)$ of 40 (Fig. 2 and Table 1).

The disruption of HCMV regulation of gene expression was implicated as a mechanism for the NMS-873-dependent reduction in virus replication [16]. Expression of the immediate-early protein 2 (IE2), a major viral gene expression factor, was reduced in infected and NMS-873treated cells [16]. An interesting aspect of a possible

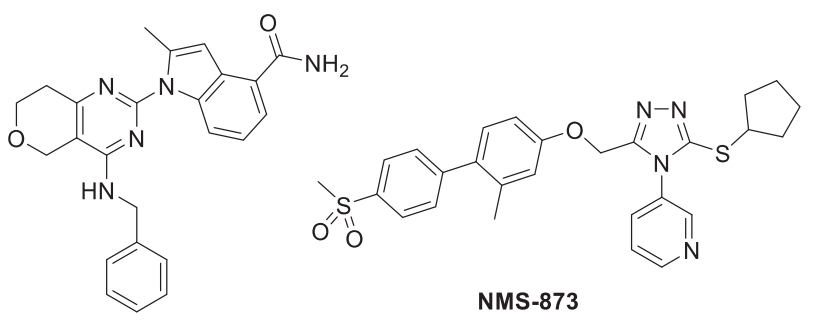

CB-5083

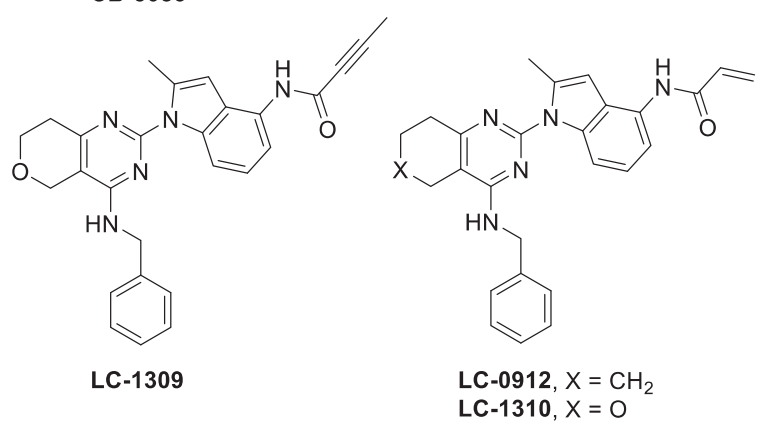

Fig. 1 Selected p97 inhibitors 

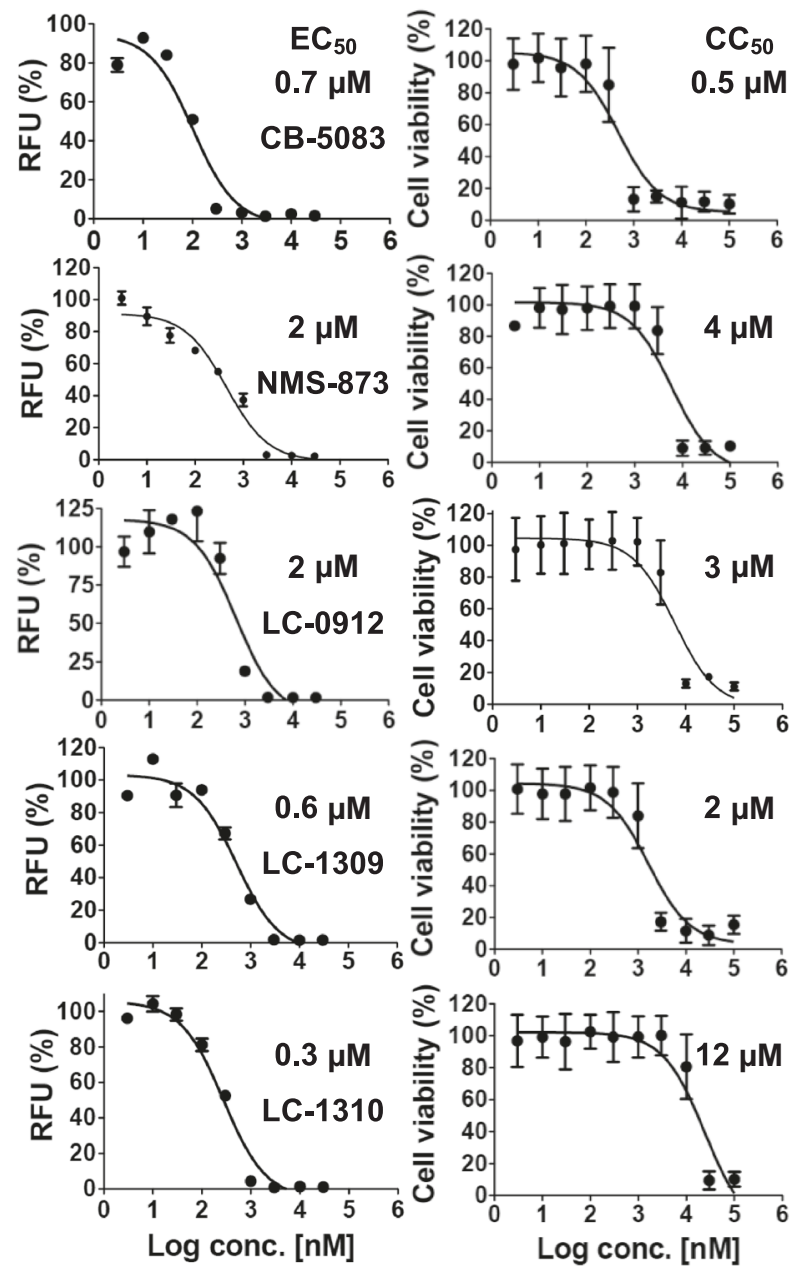

Fig. 2 Dose-response analysis of p97 inhibitors for anti-HCMV activity. Dose-response analysis of p97 inhibitors for anti-HCMV activity. HFFs were inoculated with GFP reporter HCMV and then the compound was added. Six days later, cells were lysed and GFP expression determined. (RFU relative fluorescence units). For cell viability determination, the compound was added to HFFs and 6 days later cell viability measured by an MTS assay. The $\mathrm{EC}_{50}$ (left graph) and $\mathrm{CC}_{50}$ (right graph) values and curves were determined by comparing mean activity for nine or ten serial dilutions of compound and vehicle (DMSO)-treated cells using GraphPad Prism software. The values listed are the mean of 2-3 dose-response determinations (also listed in Table 1) and representative graphs for each compound are shown

Table 1 HCMV replication assay p97 inhibitors

\begin{tabular}{lccc}
\hline Compounds & $\mathrm{EC}_{50}(\mu \mathrm{M}) \pm$ s.d. $^{\mathrm{a}}$ & $\mathrm{CC}_{50}(\mu \mathrm{M}) \pm$ s.d. $^{\mathrm{a}}$ & $\mathrm{TI}^{\mathrm{b}}$ \\
\hline NMS-873 & $2.2 \pm 2.5$ & $4.1 \pm 3.3$ & 1.9 \\
CB-5083 & $0.72 \pm 1.1$ & $0.53 \pm 0.1$ & 0.7 \\
LC-0912 & $2.1 \pm 2.5$ & $3.3 \pm 2.3$ & 1.6 \\
LC-1309 & $0.6 \pm 0.2$ & $2 \pm 0$ & 3.3 \\
LC-1310 & $0.3 \pm 0$ & $12 \pm 10$ & 40 \\
\hline
\end{tabular}

${ }^{\text {a }}$ s.d. standard deviation

${ }^{\mathrm{b}}$ Tissue culture therapeutic index $\left(\mathrm{CC}_{50} / \mathrm{EC}_{50}\right)$

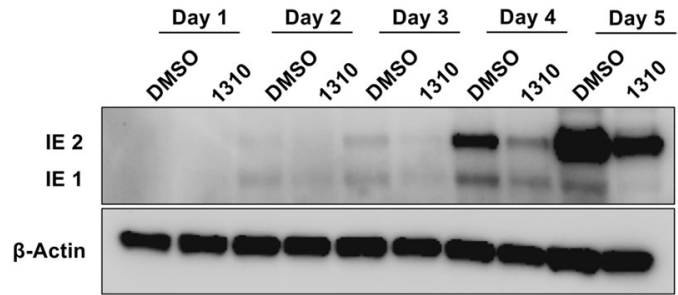

Fig. 3 HCMV IE1 and IE2 protein expression following LC-1310 treatment. Expression of IE1 and IE2 proteins during HCMV infection in the presence or absence of p97 inhibitor LC-1310. Parallel HFF cultures were inoculated, compounds added and cells processed for western blotting each day post-inoculation. The cell lysates were separated by polyacrylamide gel electrophoresis on a $10 \%$ gel and then transferred to a PVDF membrane. IE1 and 2 are detected using an antiHCMV IE1/IE2 monoclonal antibody. The $\beta$-actin levels were detected using a rabbit anti- $\beta$-Actin monoclonal antibody and are shown as a loading and expression control

mechanism of action for NMS-873 was that the viral immediate-early protein 1 (IE1) expression was not affected by NMS-873 treatment [16]. IE1 and IE2 are expressed from the same viral mRNA by differential splicing and alternative polyadenylation such that both proteins share the first three exons [33]. An NMS-873 effect on IE2 but not IE1 expression may indicate a role for p97 in splicing or polyadenylation. To examine a possible effect of LC-1310 treatment on IE1 and IE2 expression, we treated parallel infected HFFs with LC-1310 for 5 days while processing the cells for western blotting each day. Figure 3 shows that both IE1 and IE2 expression were reduced compared to the DMSO control starting at day 2 and continuing through day 5. Our result with LC-1310 differs slightly from what was published by Lin et al. using NMS-873 in that we observed a reduction in both IE1 and IE2 protein expression upon treatment with p97 inhibitor LC-1310. The simultaneous reduction in IE1 and IE2 expression could explain the increased antiviral activity and a higher therapeutic index of LC-1310 in comparison with NMS-873. Furthermore, a combined IE1/IE2 effect could be specific to LC-1310 and signal a difference in p97 inhibition or off-target effects between LC-1310 and NMS-873. LC-1310 and NMS-873 employ different mechanisms of action as p97 inhibition; NMS-873 binds in a tunnel between D1 and D2 inducing an allosteric inhibition of $\mathrm{P} 97$ [8, 9]. In contrast, the irreversible inhibitor LC-1310 was designed based on CB-5083, which targets the D2 ATP binding site [10], such that the extent and duration of p97 inhibition for LC-1310 could result in an enhanced anti-HCMV effect [28]. Also, in our experiments, we did not pretreat the HFFs prior to inoculation because it did not make a difference in NMS-873 HCMV inhibition [16].

Ganciclovir (GCV) is a front-line drug prescribed to treat HCMV infection and we were interested to examine how a combination of LC-1310 and GCV would impact inhibition 

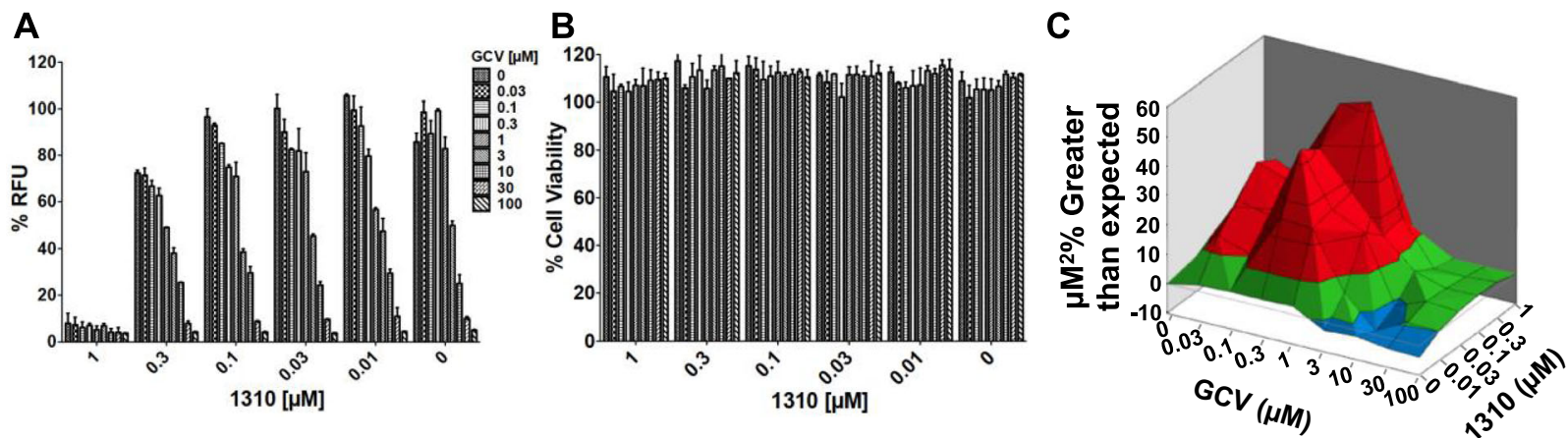

Fig. 4 LC-1310/GCV combination effects. a Anti-HCMV activities of the combinations. HFFs were inoculated as described in the HCMV replication assay and compound combinations applied. Six days later, GFP fluorescence was measured as an indication of virus replication and spread. Inhibitory effects of combinations were expressed as a percentage of the DMSO-alone samples. All compounds doses were performed in duplicate and mean value plus standard error depicted. b The viability of HFFs following compound combination treatment for 6 days was determined by the MTS viability assay and presented as a percentage of the viability of cells that were treated with DMSO

of HCMV replication in cell culture. HFFs were inoculated with ADCREGFP reporter HCMV and various combinations of six LC-1310 concentrations $(0-1 \mu \mathrm{M})$ and nine GCV concentrations $(0-100 \mu \mathrm{M})$ were added to a 96 -well plate using a six by nine matrix. After 6 days, the cultures were lysed and GFP fluorescence measured as an indication of HCMV replication and spread. The results in Fig. 4a show a clear antiviral activity at a single dose and combinations of the two compounds compared to DMSO alone and Fig. $4 \mathrm{~b}$ indicates no significant effects on cell viability at the single dose or combination concentrations. The results were used to investigate possible synergy or antagonism by the Bliss independence model using MacSynergy II software [34]. In general, the three-dimensional surface plot of the anti-HCMV activities for the combinations will show synergy via peaks above a plane representing additive effects and antagonism via depressions below the additive plane [34]. The volumes of synergy and antagonism across all tested combinations are shown in Fig. $4 \mathrm{c}$ and result in a score of 261 (95\% confidence interval), with anything above 40 considered synergistic. Therefore, the LC-1310 and GCV combination resulted in a synergistic inhibitory effect on HCMV replication.

We next combined LC-1310 and the recently approved HCMV drug Letermovir (LTV) to evaluate co-treatment potential for the $\mathrm{p} 97$ inhibitor. HFFs were inoculated with ADCREGFP reporter HCMV and various combinations of six LC-1310 concentrations $(0-1 \mu \mathrm{M})$ and nine LTV concentrations $(0-100 \mu \mathrm{M})$ were added to a 96 -well plate using a six by nine matrix. After 6 days, the cultures were lysed and GFP fluorescence measured to indicate HCMV replication and spread. There were clear antiviral effects for compounds alone and in combination (Fig. 5a) without significant cellular alone. c Three-dimensional surface plots of LC-1310 and ganciclovir combinations and anti-HCMV activities. The three-dimensional plot was generated using MacSynergy II software with the compound concentrations shown on the $x$ and $y$ axes. The horizontal plane represents the predicted surface if the interactions are additive. A peak above the additive plane represents synergy and a negative depression below the plane represents antagonism. Each sample was performed in duplicate and $95 \%$ confidence intervals were used to evaluate the data. Blue color $=-10$ to 0 , green $=0-10$, and red $=10-60 \mu \mathrm{M}^{2} \%$ for a given combination

toxicity (Fig. 5b). When we examined the results for possible synergistic or antagonistic effects using MacSynergy, the score was 30 and fell within the additive range ( -10 to 40 , Fig. 5c). Therefore, the LC-1310 and LTV combination resulted in an additive inhibitory effect on HCMV replication.

IAV is an orthomyxovirus. Viral particles are enveloped and contain a segmented single-stranded negative-sense RNA genome. The IAV RNA genome segments are contained within eight ribonucleoproteins that must be transported to the infected cell nucleus to express viral proteins. IAV is another virus where $\mathrm{p} 97$ expression is important for virus replication and NMS-873 inhibits virus production [20]. We analyzed our p97 inhibitors for effects on IAV using MDCK cells in a viral cytopathic effects (CPE) assay. We inoculated cells for 2 hours with IAV isolate $\mathrm{A} / \mathrm{WS} / 33(\mathrm{H} 1 \mathrm{~N} 1)$, retired the inoculum, and added compounds at $0.1,0.25$, and $0.5 \mu \mathrm{M}$ final concentrations. Twenty-four hours later, the infected and treated cultures were analyzed in parallel to the compoundtreated and uninfected cultures for cell viability. An antiviral compound will inhibit virus-induced CPE and promote cell viability. We normalized results for each compound to the uninfected DMSO vehicle control where we will see maximum cell viability and to the infected DMSO control where maximum virus-induced CPE will be observed. Clear antiviral effects and retention of cell viability were seen for the control inhibitor, anti-IAV nucleobase T-1105 (at $12.5 \mu \mathrm{M}$ ), and for NMS-873 (Table 2) in agreement with previously published studies $[20,35]$. There was no detectable anti-IAV activity for the p97 inhibitors LC-0912, LC-1309, LC-1310, or CB-5083 (Table 2). It is unclear if the lack of IAV activity for the compounds that bind to the D2 ATP binding site is due to a qualitative or quantitative difference in $\mathrm{p} 97$ binding compared to NMS-873 or simply an issue with those compounds 

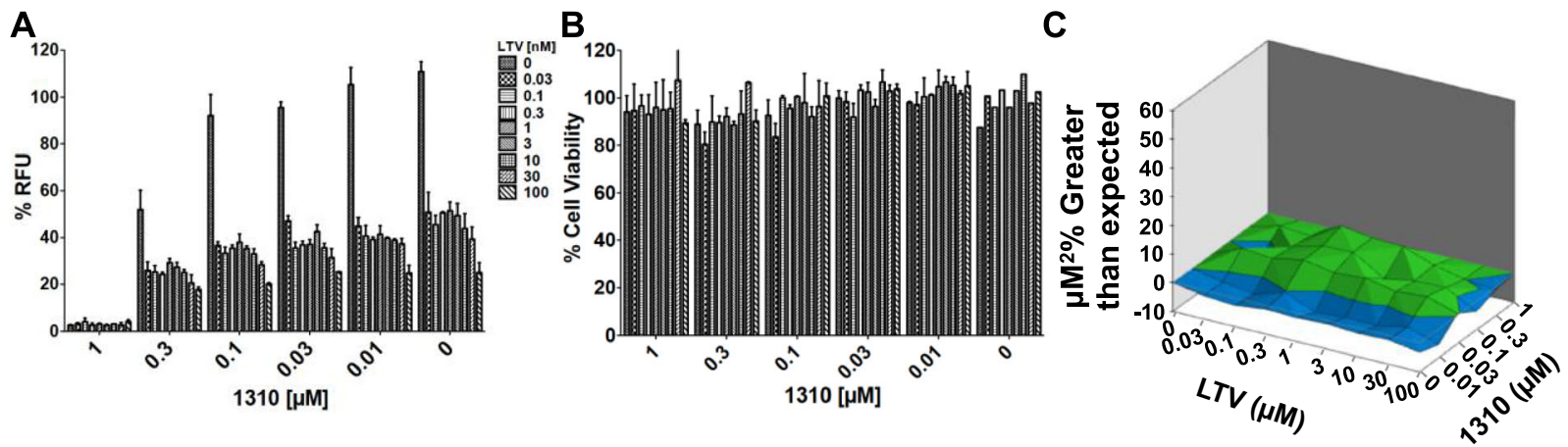

Fig. 5 LC-1310/LTV combination effects. a Anti-HCMV activities of the combinations. HFFs were inoculated as described in the HCMV replication assay and compound combinations applied. Six days later, GFP fluorescence was measured as an indication of virus replication and spread. Inhibitory effects of combinations were expressed as a percentage of the DMSO-alone samples. All compounds doses were performed in duplicate and the mean value plus standard error depicted. b The viability of HFFs following compound combination

treatment for 6 days was determined by the MTS viability assay and presented as a percentage of the viability of cells that were treated with DMSO alone. c Three-dimensional surface plots of LC-1310 and Letermovir combinations and anti-HCMV activities are shown. The three-dimensional plots were generated and interpreted as described in Fig. 4 legend. Blue color $=-10$ to 0 and green $=0-10 \mu \mathrm{M}^{2} \%$ for a given combination

Table 2 Influenza A CPE assay p97 inhibitors

\begin{tabular}{lrrrrrrr}
\hline & \multicolumn{3}{l}{${\text { Compound }+ \text { Virus }^{\mathrm{a}}}$ Compound } & & & Compound only $^{\mathrm{a}}$ \\
\cline { 2 - 3 } \cline { 7 - 8 } & $0.5 \mu \mathrm{M}$ & $0.25 \mu \mathrm{M}$ & $0.1 \mu \mathrm{M}$ & & $0.5 \mu \mathrm{M}$ & $0.25 \mu \mathrm{M}$ & $0.1 \mu \mathrm{M}$ \\
\hline DMSO & $0 \pm 4$ & $0 \pm 1$ & $0 \pm 2$ & & $100 \pm 2$ & $100 \pm 3$ & $100 \pm 0.7$ \\
T-1105 12.5 $\mu \mathrm{M}$ & $100 \pm 3$ & $98 \pm 2$ & $73 \pm 1$ & & $91 \pm 5$ & $80 \pm 1$ & $89 \pm 4$ \\
NMS-873 & $80 \pm 5$ & $62 \pm 6$ & $21 \pm 7$ & & $94 \pm 2$ & $80 \pm 2$ & $89 \pm 3$ \\
CB-5083 & $0 \pm 1$ & $0 \pm 2$ & $0 \pm 3$ & & $89 \pm 4$ & $89 \pm 2$ & $97 \pm 3$ \\
LC-0912 & $0 \pm 5$ & $0 \pm 3$ & $0 \pm 3$ & & $103 \pm 1$ & $93 \pm 2$ & $101 \pm 4$ \\
LC-1309 & $0 \pm 5$ & $0 \pm 2$ & $0 \pm 3$ & & $102 \pm 2$ & $90 \pm 4$ & $96 \pm 4$ \\
LC-1310 & $0 \pm 5$ & $1 \pm 1$ & $0 \pm 1$ & & $101 \pm 1$ & $84 \pm 2$ & $93 \pm 2$ \\
\hline
\end{tabular}

${ }^{a}$ Percent viable cells \pm standard deviation

binding the D2 ATP site in p97 from canine MDCK cells. In general, there were reduced effects for all compounds on cell viability in the absence of virus possibly due to the use of MDCK cells or the shorter 24-h treatment compared to multiple days for the other assays.

Coronaviruses are enveloped viruses with a large singlestranded plus sense viral genomic RNA (typically 26-32 kb). Upon entry into the cytoplasm, the RNA genome is translated into two large polyproteins that are cleaved by viral proteases into their effector proteins. In addition, genes near the $3^{\prime}$ end of the viral genome are expressed via subgenomic viral RNAs. Coronaviruses are significant human pathogens causing outcomes from a common cold-like illness to severe acute respiratory syndrome (SARS) and with the emergence of SARS-CoV-2 there is renewed interest in anti-CoV therapeutics. In addition, siRNA-mediated knockdown of $\mathrm{p} 97$ expression resulted in a reduction in infectious bronchitis virus (IBV) $\mathrm{CoV}$ replication, indicating the importance of $\mathrm{p} 97$ function for IBV and possibly other CoV [15]. We tested the irreversible p97 inhibitors for their effects on human coronavirus OC43 (HCoV-OC43), a betacoronavirus that can cause a cold-like illness in humans [36]. We inoculated human hepatocellular carcinoma Huh7 cells with $\mathrm{HCoV}$ OC43, retired the inoculum, and incubated the cultures with the compound for 5 days. HCoV-OC43 will cause extensive CPE in Huh-7 cultures by day 5 unless virus replication is inhibited. We included three concentrations of compound, $0.1,0.25$, and $0.5 \mu \mathrm{M}$. None of the compounds showed an antiviral effect against $\mathrm{HCoV}-\mathrm{OC} 43$ (Table 3) whereas the broad-spectrum nucleoside inhibitor remdesivir (RDV) showed $100 \%$ protection at $1 \mu \mathrm{M}$ as expected [37]. It could be that IBV, a gammacoronavirus of chickens, is more susceptible to p97 inhibition in cell culture than the betacoronavirus $\mathrm{HCoV}-\mathrm{OC} 43$. The p97 inhibitors caused a $10-60 \%$ reduction in cell viability at 0.5 and $0.25 \mu \mathrm{M}$ and NMS-873 showed a clear effect on cell viability additionally at $0.1 \mu \mathrm{M}$ (Table 3 ).

\section{Conclusion}

The ring ATPase p97 is an attractive target for antiviral therapeutics. The challenge is to develop a p97 inhibitor 
Table 3 HCoV-OC43 CPE assay p97 inhibitors

\begin{tabular}{|c|c|c|c|c|c|c|}
\hline \multirow[b]{2}{*}{ Compound } & \multicolumn{3}{|c|}{ Compound + Virus $^{\mathrm{a}}$} & \multicolumn{3}{|c|}{ Compound only ${ }^{\mathrm{a}}$} \\
\hline & $0.5 \mu \mathrm{M}$ & $0.25 \mu \mathrm{M}$ & $0.1 \mu \mathrm{M}$ & $0.5 \mu \mathrm{M}$ & $0.25 \mu \mathrm{M}$ & $0.1 \mu \mathrm{M}$ \\
\hline DMSO & $0 \pm 2$ & $0 \pm 7$ & $0 \pm 5$ & $100 \pm 4$ & $100 \pm 3$ & $100 \pm 0.3$ \\
\hline RDV $1 \mu \mathrm{M}$ & $100 \pm 4$ & $100 \pm 6$ & $100 \pm 1$ & $100 \pm 1$ & $104 \pm 2$ & $103 \pm 2$ \\
\hline NMS-873 & $0 \pm 1$ & $0 \pm 1$ & $0 \pm 1$ & $42 \pm 4$ & $54 \pm 2$ & $59 \pm 1$ \\
\hline CB-5083 & $0 \pm 1$ & $0 \pm 2$ & $0 \pm 3$ & $38 \pm 1$ & $59 \pm 3$ & $83 \pm 1$ \\
\hline LC-0912 & $0 \pm 1$ & $0 \pm 3$ & $0 \pm 3$ & $57 \pm 4$ & $90 \pm 3$ & $95 \pm 2$ \\
\hline LC-1309 & $0 \pm 3$ & $0 \pm 2$ & $0 \pm 3$ & $47 \pm 2$ & $78 \pm 2$ & $86 \pm 1$ \\
\hline LC-1310 & $0 \pm 1$ & $0 \pm 6$ & $0 \pm 3$ & $78 \pm 8$ & $89 \pm 2$ & $86 \pm 2$ \\
\hline
\end{tabular}

${ }^{a}$ Percent viable cells \pm standard deviation without complicating cellular toxicity. We describe here an irreversible p97 inhibitor, LC-1310, that potently inhibits HCMV replication with a better cellular toxicity profile than other known p97 inhibitors. The activity appears to be selective for HCMV and may differ mechanistically from the inhibition observed for NMS-873.

\section{Methods}

\section{Compounds}

p97 inhibitors were synthesized as previously described [28]. RDV (CAS\# 1809249-37-3) was purchased from MedKoo Biosciences, Inc. T-1105 (3-hydroxypyrazine-2-carboxamide, CAS\# 55321-99-8) was purchased from Alfa Aesar. All compounds were stored at $-20{ }^{\circ} \mathrm{C}$ as $20 \mathrm{mM}$ stock solutions in dimethyl sulfoxide (DMSO) shortly before use.

\section{Cells and viruses}

The hepatocyte-derived cellular carcinoma cell line Huh-7 [38] was used for HCoV-OC43 studies. Huh-7 cells were maintained in minimum essential medium supplemented with $10 \%$ fetal bovine serum (FBS), 100 IU streptomycin/ penicillin per $\mathrm{ml}, 1 \mathrm{mM}$ Sodium pyruvate, $1 \mathrm{X}$ non-essential amino acids, and $10 \mu \mathrm{g} / \mathrm{mL}$ plasmocin (InvivoGen). Human foreskin fibroblasts (HFFs, CRL-2088) and Madin-Darby Canine Kidney cells (CCL-34) were obtained from American Type Tissue Culture (ATCC). HFF and MDCK were maintained in Dulbecco's modified Eagle's medium (DMEM) supplemented with 10\% fetal bovine serum (FBS) (7\% for MDCK cells), $100 \mathrm{IU}$ streptomycin/penicillin per $\mathrm{ml}$, and $10 \mu \mathrm{g} / \mathrm{mL}$ plasmocin (InvivoGen). All the cell lines were maintained at $37{ }^{\circ} \mathrm{C}$ in a $5 \% \mathrm{CO}_{2}$ incubator. The GFP reporter virus derived from the lab strain HCMV AD169 strain, ADCREGFP was provided by Wade Bresnahan (University of Minnesota) [29]. HCoV-OC43 was provided by Jun Wang (University of Arizona). IAV A/WS/ 33 (H1N1) was obtained from ATCC (VR-825).

\section{HCMV virus replication assay}

This assay measures GFP expression from an HCMV reporter virus, ADCREGFP, and has been described previously [30-32, 39]. Briefly, $\sim 3 \times 10^{4} \mathrm{HFFs} /$ well were plated into 96-well white opaque dishes and inoculated with ADCREGFP the next day at a multiplicity of infection (MOI) of 0.001 in DMEM containing 5\% fetal calf serum for $2 \mathrm{~h}$ at $37{ }^{\circ} \mathrm{C}$ and $5 \% \mathrm{CO}_{2}$. The cells were then washed with phosphate-buffered saline (PBS) and $100 \mu \mathrm{l}$ of DMEM containing $5 \%$ fetal calf serum with test compounds or DMSO was added and maintained at $37{ }^{\circ} \mathrm{C}$ and $5 \% \mathrm{CO}_{2}$ for 6 days. The infected cells were then lysed for $10 \mathrm{~min}$ at $37^{\circ} \mathrm{C}$ with $200 \mu$ lysis buffer $(25 \mathrm{mM}$ Tris [pH 7.8], $2 \mathrm{mM}$ dithiothreitol (DTT), $2 \mathrm{mM}$ trans-1,2-diaminocyclohexane$\mathrm{N}, \mathrm{N}, \mathrm{N}^{\prime}, \mathrm{N}^{\prime}$-tetraacetic acid, $1 \%$ Triton X-100, $10 \%$ glycerol) followed by a $30 \mathrm{~min}$ incubation at room temperature on a shaker $[30,40,41]$. GFP relative fluorescence units were determined at excitation/emission $495 / 515 \mathrm{~nm}$ in a Molecular Devices M5e plate reader. Mean values of triplicate wells were determined and compared to the mean value for the wells that received DMSO alone. The concentration of compound that reduced luciferase activity by $50 \%$ was defined as the $50 \%$ effective concentration $\left(\mathrm{EC}_{50}\right)$. The $\mathrm{EC}_{50}$ was determined by comparing luciferase activity for nine serial dilutions of the compound and vehicle-treated cells using GraphPad Prism software.

For the compound combination studies, cells inoculated as above were incubated with compounds alone and in various combinations in a six by nine matrix in 96-well plates. The infected and compound-treated cells were processed as above. The data were analyzed using the MacSynergy II software [34]. The synergy values were obtained at the $95 \%$ confidence interval.

\section{Cell viability assay}

HFFs were plated into 96-well plates as indicated in HCMV replication assay and the next day incubated in different compound doses at $37^{\circ} \mathrm{C}$ for 6 days. The 
3-(4,5-dimethylthiazol-2-yl)-5-(3-carboxymethoxyphenyl)2-(4-sulfophenyl)-2H-tetrazolium (MTS)-based tetrazolium reduction CellTiter 96 Aqueous Non-Radioactive cell proliferation assay (Promega G5430) was used as per manufacturer's instructions to determine cell viability. Each compound dose was tested in triplicate and the mean values of the triplicates were compared to the mean value for the wells treated with DMSO alone. Data from ten serial dilutions of the compound were used to calculate the $\mathrm{CC}_{50}$ using GraphPad Prism software. The $\mathrm{CC}_{50}$ value was the concentration of the compound resulting in a $50 \%$ viability reduction compared to DMSO.

\section{Western blotting}

HFFs were grown in 12-well tissue culture plates at $\sim 3.6 \times$ $10^{5}$ cells per well. Cells were incubated with the compound before virus inoculation. After $24 \mathrm{~h}$ incubation, cells were inoculated with ADCREGFP virus for 2 hours at an MOI of 0.1 in DMEM containing 5\% fetal bovine serum. The inoculated cells were washed with phosphate-buffered saline and incubated with DMEM containing 5\% fetal bovine serum with test compounds or DMSO at $37^{\circ} \mathrm{C}$ and $5 \% \mathrm{CO}_{2}$ for $120 \mathrm{~h}$. The infected cells were lysed with RIPA buffer (0.1\% SDS, $1 \%$ Triton X-100, $1 \%$ deoxycholate, $5 \mathrm{mM}$ EDTA, $150 \mathrm{mM} \mathrm{NaCl}$, and $10 \mathrm{mM}$ Tris at $\mathrm{pH}$ 7.2). Twenty micrograms of total lysate protein were separated by electrophoresis on a $10 \%$ SDS-polyacrylamide gel and transferred to a PVDF membrane (Millipore). Primary antibodies were mouse anti-CMV IE1/2 monoclonal antibody (MAB8131, Millipore) and rabbit anti- $\beta$-Actin monoclonal antibody (4970T, Cell Signaling). Blots were probed with primary antibody (1:2000) diluted in 5\% BSA in Tris Buffered Saline (TBS) and subsequently the HRPconjugated secondary antibodies (Anti-rabbit IgG, HRPlinked Antibody from Cell Signaling 7074S; Mouse IgG HRP Linked Whole Antibody from GE Healthcare NXA931) at 1:10,000. Blots were washed in TBS three times, incubated with chemiluminescent substrate (SuperSignal West Pico; Thermo Scientific) according to the manufacturer's protocol, and exposed in ChemiDoc MP (Bio-Rad) for visualization of bands.

\section{Human betacoronavirus $0 C 43$ cytopathic effects assay}

Huh-7 cells $\left(1.25 \times 10^{4}\right.$ per well $)$ were seeded in a regular 96-well plate and the next day the cells were inoculated with $\mathrm{HCoV}-\mathrm{OC} 43$ at an MOI of 0.5 for 2 hours at $37{ }^{\circ} \mathrm{C} 5 \%$ $\mathrm{CO}_{2}$. The inoculum was subsequently retired and the cells were treated with compounds or RDV $1 \mu \mathrm{M}$ as a positive control. Concentrations of $0.1,0.25$, and $0.5 \mu \mathrm{M}$ were tested for all the p97-targeting compounds. The percent viable cells in absence of infection were analyzed in parallel cultures. Cells were incubated for 5 days after which the infected and treated cells were analyzed for cell viability using the MTS-based tetrazolium reduction CellTiter 96 Aqueous Non-Radioactive cell proliferation assay and absorbance was measured at $490 \mathrm{~nm}$. The readings in infected cells were normalized to DMSO-treated cells $(\sim 0 \%$ viability) and RDV-treated cells ( $100 \%$ viability) via GraphPad prism. Readings for uninfected cells were normalized to DMSO control ( $100 \%$ viability).

\section{Influenza A virus cytopathic effects assay}

MDCK cells $\left(3 \times 10^{4}\right.$ per well $)$ were seeded in a 96-well plate. The next day the cells were inoculated with IAV A/ WS/33 at an MOI 0.02 for 2 hours in an IAV-infection medium (DMEM supplemented with $0.2 \% \mathrm{BSA}, 0.5 \mu \mathrm{g} /$ $\mathrm{mL}$ of TPCK-treated trypsin, 1X pen-strep, 1X glutamax, $10 \mathrm{mM}$ Hepes). After 2 hours, the inoculum was retired and compounds added in an IAV-infection medium for $24 \mathrm{~h}$. In parallel, cell viability in absence of infection was analyzed. Cell viability was determined using the MTSbased tetrazolium reduction CellTiter 96 Aqueous NonRadioactive cell proliferation assay after the 24-h incubation and absorbance was measured at $490 \mathrm{~nm}$. The readings in infected cells were normalized to DMSOtreated cells ( $\sim 0 \%$ viability) and uninfected DMSO-treated cells ( $100 \%$ viability) via GraphPad prism. Readings for uninfected cells were normalized to DMSO control $(\sim 100 \%$ viability).

Acknowledgements The authors wish to acknowledge the Center for Drug Design for support.

\section{Compliance with ethical standards}

Conflict of interest The authors declare that they have no conflict of interest.

Publisher's note Springer Nature remains neutral with regard to jurisdictional claims in published maps and institutional affiliations.

\section{References}

1. van den Boom J, Meyer H. VCP/p97-mediated unfolding as a principle in protein homeostasis and signaling. Mol Cell. 2018;69:182-94. https://doi.org/10.1016/j.molcel.2017.10.028.

2. Meyer H, Bug M, Bremer S. Emerging functions of the VCP/p97 AAA-ATPase in the ubiquitin system. Nat Cell Biol. 2012;14:117-23. https://doi.org/10.1038/ncb2407.

3. Chapman E, Maksim N, de la Cruz F, La, Clair JJ. Inhibitors of the AAA+ chaperone p97. Molecules. 2015;20:3027-49. https:// doi.org/10.3390/molecules20023027.

4. Anderson DJ, Le Moigne R, Djakovic S, Kumar B, Rice J, Wong S. et al. Targeting the AAA ATPase p97 as an approach to treat 
cancer through disruption of protein homeostasis. Cancer Cell. 2015;28:653-65. https://doi.org/10.1016/j.ccell.2015.10.002.

5. Song C, Wang Q, Li CC. ATPase activity of p97-valosincontaining protein (VCP). D2 mediates the major enzyme activity, and D1 contributes to the heat-induced activity. J Biol Chem. 2003;278:3648-55. https://doi.org/10.1074/jbc.M208422200.

6. Wang Q, Shinkre BA, Lee JG, Weniger MA, Liu Y, Chen W. et al. The ERAD inhibitor Eeyarestatin I is a bifunctional compound with a membrane-binding domain and a p97/VCP inhibitory group. PLoS ONE. 2010;5:e15479. https://doi.org/10.1371/ journal.pone.0015479.

7. Banerjee S, Bartesaghi A, Merk A, Rao P, Bulfer SL, Yan Y. et al. $2.3 \AA$ resolution cryo-EM structure of human p97 and mechanism of allosteric inhibition. Science. 2016;351:871-5. https://doi.org/ 10.1126/science.aad7974.

8. Magnaghi P, D'Alessio R, Valsasina B, Avanzi N, Rizzi S, Asa D. et al. Covalent and allosteric inhibitors of the ATPase VCP/p97 induce cancer cell death. Nat Chem Biol. 2013;9:548-56. https:// doi.org/10.1038/nchembio.1313.

9. Bastola P, Wang F, Schaich MA, Gan T, Freudenthal BD, Chou TF. et al. Specific mutations in the D1-D2 linker region of VCP/ p97 enhance ATPase activity and confer resistance to VCP inhibitors. Cell Death Discov. 2017;3:17065. https://doi.org/10.1038/ cddiscovery.2017.65.

10. Tang WK, Odzorig T, Jin W, Xia D. Structural basis of p97 inhibition by the site-selective anticancer compound CB-5083. Mol Pharm. 2019;95:286-93. https://doi.org/10.1124/mol.118.114256.

11. Zhou HJ, Wang J, Yao B, Wong S, Djakovic S, Kumar B. et al. Discovery of a first-in-class, potent, selective, and orally bioavailable inhibitor of the p97 AAA ATPase (CB-5083). J Med Chem. 2015;58:9480-97. https://doi.org/10.1021/acs.jmedchem.5b01346.

12. Huryn DM, Kornfilt DJP, Wipf P. p97: an emerging target for cancer, neurodegenerative diseases, and viral infections. J Med Chem. 2020;63:1892-907. https://doi.org/10.1021/acs.jmedchem. $9 \mathrm{~b} 01318$.

13. Frabutt DA, Zheng YH. Arms race between enveloped viruses and the host ERAD machinery. Viruses. 2016;8. https://doi.org/10. 3390/v8090255.

14. Meyer H, Weihl CC. The VCP/p97 system at a glance: connecting cellular function to disease pathogenesis. J Cell Sci. 2014;127:3877-83. https://doi.org/10.1242/jcs.093831.

15. Wong HH, Kumar P, Tay FP, Moreau D, Liu DX, Bard F. Genome-wide screen reveals valosin-containing protein requirement for coronavirus exit from endosomes. J Virol. 2015;89:11116-28. https://doi.org/10.1128/JVI.01360-15.

16. Lin YT, Prendergast J, Grey F. The host ubiquitin-dependent segregase $\mathrm{VCP} / \mathrm{p} 97$ is required for the onset of human cytomegalovirus replication. PLoS Pathog. 2017;13:e1006329. https:// doi.org/10.1371/journal.ppat.1006329.

17. Wang $\mathrm{T}$, Wang B, Huang $\mathrm{H}$, Zhang $\mathrm{C}$, Zhu Y, Pei B. et al. Enterovirus 71 protease 2Apro and 3Cpro differentially inhibit the cellular endoplasmic reticulum-associated degradation (ERAD) pathway via distinct mechanisms, and enterovirus 71 hijacks ERAD component p97 to promote its replication. PLoS Pathog. 2017;13:e1006674. https://doi.org/10.1371/journal.ppat.1006674.

18. Brahms A, Mudhasani R, Pinkham C, Kota K, Nasar F, Zamani R, et al. Sorafenib impedes rift valley fever virus egress by inhibiting valosin-containing protein function in the cellular secretory pathway. J Virol. 2017;91. https://doi.org/10.1128/JVI.00968-17.

19. Carissimo G, Chan YH, Utt A, Chua TK, Bakar FA, Merits A. et al. $\mathrm{VCP} / \mathrm{p} 97$ is a proviral host factor for replication of chikungunya virus and other alphaviruses. Front Microbiol. 2019;10:2236. https://doi.org/10.3389/fmicb.2019.02236.

20. Zhang J, Hu Y, Hau R, Musharrafieh R, Ma C, Zhou X. et al. Identification of NMS-873, an allosteric and specific p97 inhibitor, as a broad antiviral against both influenza A and B viruses. Eur J
Pharm Sci. 2019;133:86-94. https://doi.org/10.1016/j.ejps.2019. 03.020.

21. Arita M, Wakita T, Shimizu H. Valosin-containing protein (VCP/ p97) is required for poliovirus replication and is involved in cellular protein secretion pathway in poliovirus infection. J Virol. 2012;86:5541-53. https://doi.org/10.1128/JVI.00114-12.

22. Phongphaew W, Kobayashi S, Sasaki M, Carr M, Hall WW, Orba Y. et al. Valosin-containing protein $(\mathrm{VCP} / \mathrm{p} 97)$ plays a role in the replication of West Nile virus. Virus Res. 2017;228:114-23. https://doi.org/10.1016/j.virusres.2016.11.029.

23. Hao Q, Jiao S, Shi Z, Li C, Meng X, Zhang Z. et al. A non-canonical role of the p97 complex in RIG-I antiviral signaling. EMBO J. 2015;34:2903-20. https://doi.org/10.15252/embj.201591888.

24. Yi Z, Fang C, Zou J, Xu J, Song W, Du X. et al. Affinity purification of the hepatitis $\mathrm{C}$ virus replicase identifies valosin-containing protein, a member of the ATPases associated with diverse cellular activities family, as an active virus replication modulator. J Virol. 2016;90:9953-66. https://doi.org/10.1128/JVI.01140-16.

25. Yi Z, Yuan Z. Aggregation of a hepatitis $C$ virus replicase module induced by ablation of p97/VCP. J Gen Virol. 2017;98:1667-78. https://doi.org/10.1099/jgv.0.000828.

26. Lyupina YV, Erokhov PA, Kravchuk OI, Finoshin AD, Abaturova SB, Orlova OV. et al. Essential function of VCP/p97 in infection cycle of the nucleopolyhedrovirus AcMNPV in Spodoptera frugiperda Sf9 cells. Virus Res. 2018;253:68-76 https:// doi.org/10.1016/j.virusres.2018.06.001.

27. Ramanathan HN, Zhang S, Douam F, Mar KB, Chang J, Yang $\mathrm{PL}$, et al. A sensitive yellow fever virus entry reporter identifies valosin-containing protein $(\mathrm{VCP} / \mathrm{p} 97)$ as an essential host factor for flavivirus uncoating. mBio. 2020;11. https://doi.org/10.1128/ mBio.00467-20.

28. Ding R, Zhang T, Wilson DJ, Xie J, Williams J, Xu Y. et al. Discovery of irreversible p97 inhibitors. J Med Chem. 2019;62:2814-29. https://doi.org/10.1021/acs.jmedchem.9b00144.

29. Cantrell SR, Bresnahan WA. Interaction between the human cytomegalovirus UL82 gene product (pp71) and hDaxx regulates immediate-early gene expression and viral replication. J Virol. 2005;79:7792-802. https://doi.org/10.1128/jvi.79.12.7792-7802. 2005.

30. Wang Y, Mao L, Kankanala J, Wang Z, Geraghty RJ. Inhibition of human cytomegalovirus pUL89 terminase subunit blocks virus replication and genome cleavage. J Virol. 2017;91. https://doi.org/ 10.1128/jvi.02152-16.

31. Wang Y, Tang J, Wang Z, Geraghty RJ. Metal-chelating 3hydroxypyrimidine-2,4-diones inhibit human cytomegalovirus pUL89 endonuclease activity and virus replication. Antivir Res. 2018;152:10-7. https://doi.org/10.1016/j.antiviral.2018.01.015.

32. Wang Y, Geraghty RJ. FRET-based assay using a three-way junction DNA substrate to identify inhibitors of human cytomegalovirus pUL89 endonuclease activity. Eur J Pharm Sci. 2019;127:29-37. https://doi.org/10.1016/j.ejps.2018.10.016.

33. Stinski MF, Isomura $H$. Role of the cytomegalovirus major immediate early enhancer in acute infection and reactivation from latency. Med Microbiol Immunol. 2008;197:223-31. https://doi. org/10.1007/s00430-007-0069-7.

34. Prichard MN, Shipman C Jr. A three-dimensional model to analyze drug-drug interactions. Antivir Res. 1990;14:181-205.

35. Furuta Y, Takahashi K, Shiraki K, Sakamoto K, Smee DF, Barnard DL. et al. T-705 (favipiravir) and related compounds: novel broad-spectrum inhibitors of RNA viral infections. Antivir Res. 2009;82:95-102. https://doi.org/10.1016/j.antiviral.2009.02.198.

36. Bradburne AF, Bynoe ML, Tyrrell DA. Effects of a "new" human respiratory virus in volunteers. Br Med J. 1967;3:767-9. https:// doi.org/10.1136/bmj.3.5568.767.

37. Brown AJ, Won JJ, Graham RL, Dinnon KH, Sims AC, Feng JY. et al. Broad spectrum antiviral remdesivir inhibits human endemic 
and zoonotic deltacoronaviruses with a highly divergent RNA dependent RNA polymerase. Antivir Res. 2019;169:104541 https://doi.org/10.1016/j.antiviral.2019.104541.

38. Nakabayashi H, Taketa K, Miyano K, Yamane T, Sato J. Growth of human hepatoma cells lines with differentiated functions in chemically defined medium. Cancer Res. 1982;42:3858-63.

39. Kankanala J, Wang Y, Geraghty RJ, Wang Z Hydroxypyridonecarboxylic acids as inhibitors of human cytomegalovirus pUL89 endonuclease. ChemMedChem. 2018. https://doi.org/10. 1002/cmdc.201800283.
40. Dal Pozzo F, Andrei G, Daelemans D, Winkler M, Piette J, De Clercq E. et al. Fluorescence-based antiviral assay for the evaluation of compounds against vaccinia virus, varicella zoster virus and human cytomegalovirus. J Virol Methods. 2008;151:66-73. https://doi.org/10.1016/j.jviromet.2008.03.025.

41. Marschall M, Freitag M, Weiler S, Sorg G, Stamminger T. Recombinant green fluorescent protein-expressing human cytomegalovirus as a tool for screening antiviral agents. Antimicrob Agents Chemother. 2000;44:1588-97. 